\title{
Drivers of teachers' intentions to use mobile applications to teach science
}

\author{
Hüseyin Ateş ${ }^{1}$ [ Juan Garzón ${ }^{2} \mathbb{D}$
}

Received: 23 May 2021 / Accepted: 12 July 2021 / Published online: 26 August 2021

(c) The Author(s), under exclusive licence to Springer Science+Business Media, LLC, part of Springer Nature 2021

\begin{abstract}
Using mobile applications in science education has proven to be effective as it adds multiple benefits including learning gains, motivation to learn, and collaborative learning. However, some teachers are reluctant to use this technology for reasons derived from different factors. Hence, it is important to identify what factors affect teachers' intentions to use mobile applications, in order to take actions aiming to encourage them to use this technology in their classes. Accordingly, this study proposes a model to predict science teachers' intentions to use mobile applications in the teaching process. Our model merges the Technology Acceptance Model, the Flow Theory, and the Theory of Planned Behavior. It includes 11 hypotheses that were tested with 1203 pre-service and in-service science teachers from different cities in Turkey. Additionally, the study investigates the mediating role of attitude and perceived usefulness on teachers' intentions to use mobile apps. Further, it examines the moderating role of the sample type on teachers' behavioral intentions. The results indicate that all 11 hypotheses were significant to explain teachers' intentions to use mobile applications. Finally, the study raises theoretical and practical implications to guide stakeholders to undertake actions to enrich educational settings through the use of mobile applications.
\end{abstract}

Keywords Flow Theory · Mobile application · Science Education · Technology Acceptance Model · Theory of Planned Behavior

Hüseyin Ateş

huseyin.ates@ahievran.edu.tr

1 Department of Science Education, Kırşehir Ahi Evran University, Kırşehir 40100, Turkey

2 Faculty of Engineering, Universidad Católica de Oriente, Rionegro, Colombia 


\section{Introduction}

The use of mobile applications (mobile apps) in education has positively transformed teaching and learning processes. As for science education, using mobile apps has proven to be effective as it adds multiple benefits including learning gains, motivation to learn, and collaborative learning (Bano et al., 2018; Camilleri \& Camilleri, 2019; Crompton et al., 2016; Martín-Páez et al., 2019). However, some teachers are reluctant to use these technological aids for reasons derived from different factors (Al-Azawei \& Alowayr, 2020; Bano et al., 2018; Kalogiannakis \& Papadakis, 2019). Therefore, it is important to identify the factors affecting their intentions to use mobile apps, in order to take actions aiming to encourage them to use this technology in their classes. Science education involves similar academic contents and structure throughout the world; nonetheless, every country has different strategies to address this subject depending on political and cultural influences. In this study, we consider the Turkish model of science education. The curriculum for this model includes physical processes; life and living beings; and the earth and the universe and is taught in grades 5 to 8 (Turkish Ministry of National Education, 2018).

Some studies have focused on the analysis of the status, trends, advantages, and challenges of mobile apps in science education (Crompton et al., 2016). However, the existing literature lacks studies that identify teachers' intentions to adopt and use this technology in the teaching process. Hence, this study proposes a model to predict science teachers' intentions to use mobile apps in their classes. Our model merges three psychological-based behavioral theories, namely the Technology Acceptance Model (TAM), the Flow Theory (FT), and the Theory of Planned Behavior (TPB). Merging these theories provides theoretical and practical insights to guide stakeholders to undertake actions to enrich educational settings through the use of mobile applications. The TAM has been described as the most powerful theory to predict an individual's intention to adopt a specific technology (Hansen et al., 2018). On its part, the emotional constructs of the FT, help identify which factors are most likely to influence teachers' motivation to use mobile apps. Finally, the rational considerations of the TPB help understand how science teachers evaluate the cost-benefit relationship of using mobile apps. Hence, we postulate that merging these theories is relevant to examine associations between constructs to explain science teachers' intentions to use mobile apps in educational settings.

To our knowledge, this is the first study to predict teachers' intention to use mobile apps in science education in the Turkish context. However, our results can be generalized to the global context to guide the process of integrating mobile apps in the educational settings. The study compares the explanatory power of the proposed model with that of the TAM, FT, and TPB. It also examines the relative importance among the constructs to understand teachers' intentions to use mobile apps for science teaching. Additionally, it investigates the mediating role of attitude and perceived usefulness on teachers' intentions to use mobile apps. Further, the study examines the moderating effect of sample type within the research 
framework. Finally, the study raises some theoretical and practical implications to guide stakeholders to undertake actions aimed at enriching educational settings using mobile applications.

\section{Literature review and study hypotheses}

\subsection{Mobile apps in science education}

The study by Crompton et al. (2016) analyzed 49 studies to identify the trends in the use of mobile applications in science education. The study found that elementary schools are the most common setting for research studies and that most studies focus on life sciences. Furthermore, the authors found that the majority of the studies take place in informal educational contexts and use smartphones as deployment technology. As for the benefits of using mobile apps in science, the study by Zydney and Warner (2016) establishes that perhaps the main benefit is learning gains. Furthermore, the study asserts that this technology can be used in situated learning contexts, which translates into knowledge retention and learning transfer. Similarly, the study by Jeno et al. (2019) employed the Self-Determination Theory to analyze the impact of mobile apps compared to traditional textbooks in science education. The study concluded that mobile applications extend the learning space, which facilitates collaboration and promotes interaction with course content, improving students' learning and motivation. Finally, Bano et al. (2018) conducted a systematic review of 49 studies to identify the pedagogical approaches adopted when using mobile apps in education. The results indicate that collaborative learning is the most reported approach in the studies. Using mobile apps allows students to interact with their partners facilitating the understanding of abstract concepts from science, which raises collaborative learning as an important benefit of the use of mobile apps in science education.

Some studies have analyzed the factors that affect teachers' intentions to use mobile technologies in science-related fields. The study by Udeani and Akhigb (2020) investigated in-service biology teachers' perceptions of the use of smartphones in educational settings. The study included 32 in-service biology teachers, from a secondary school in Nigeria. The study considered the TAM questionnaire and the Mobile App Selection for Science (MASS) rubric. As a result, the study found that in-service biology teachers in Nigeria have positive perceptions about the pedagogical use mobile apps and that these perceptions are significant in their intentions to use the apps in educational settings. Similarly, the study by Kalogiannakis and Papadakis (2019) implemented the TAM to identify how the skills and attitude towards technology, affect teachers' willingness to use mobile devices to teach natural sciences in kindergarten. The study included 75 pre-service kindergarten teachers from Greece. The results indicated that the pre-service teachers' attitude toward the usefulness of mobile learning and their perceived ease of use had the strongest influence on their intention to use this technology in classes. Finally, the study by Khlaif (2018) investigated the factors influencing the adoption and acceptance of tablets as a mobile technology in middle schools in Palestine. The study included 
15 teachers who were interviewed following an instrument designed according to the Unified Theory of Acceptance and Use of Technology (UTAUT). The results indicated that teachers' attitudes are a critical factor in accepting tablet use in classroom, and in turn, their attitudes are influenced by the perception of technical support, instructional assistance, and infrastructure.

However, the aforementioned studies have some important limitations according to the purpose of our study. First,

the studies focused on one subject or one target group, which does not let them to accurately stablish general statements that advance the broad field of science education. Second these studies use relatively small samples, limiting their findings to a very specific context. Third, the studies use a single psychological-based behavioral theory. This implies that they do not complement the predictive power with the inclusion of additional theories, as suggested in previous studies (Manosuthi et al., 2020; Tamilmani et al., 2017; Taufique \& Vaithianathan, 2018).

\subsection{Proposed model}

This study proposes a model to predict science teachers' intentions to use mobile applications in the teaching process. To our purpose, it is necessary to identify both the behavioral intentions and actual behaviors of science teachers. This implies identifying both direct and indirect factors that influence teachers' attitudes, which in turn, lead to behavior (Hill, 2017). These factors may include extrinsic and intrinsic attributes like social norms, compliance intentions, normative believes, perceived usefulness, perceived ease of use, perceived enjoyment, perceived cost-benefit relationship, and perceived self-efficacy to comply (Hofeditz et al., 2017). No psychological-based theory includes the analysis of all the factors mentioned above. Therefore, it is suitable to consider a combination of theories, which together produce a more robust theory to explain individuals' intentions to adopt a specific behavior (Hansen et al., 2018). In addition, as explained in previous studies, merging two or more behavioral theories, often increases the power to explain individuals' intentions that, ultimately, predicts individuals' behavior.

Our model combines the TAM, FT, and TPB for three main reasons. First, TAM has become one of the most widely used models in technology-enhanced learning, due in part, because its simplicity and understandability. However, the fact that TAM employs only two constructs to explain behavioral intention, results in significant variation in the predicted effects between studies with different types of users and systems (Legris et al., 2003). Consequently, it is recommended to use the TAM jointly with other models, in order to extend its explanatory power (Lu et al., 2009). Second, perhaps the main advantage of the TPB is that it helps identify the direct determinants and the underlying beliefs that impact the individuals' intentions to perform a specific behavior (Cheng, 2019). However, this framework fails to provide information on the attitudinal beliefs that would affect users' attitudes toward the use of a specific system, thus requiring it to be complemented with other theories. Third, the FT focuses on the motivational aspects that lead to adopt a specific system. Different studies have shown that concerning educational contexts, motivation 
is as important as knowledge (Keller, 2009). When using mobile apps, individuals can experience the flow while being involved in educational scenarios. Therefore, we posit that using the FT is also applicable to explain teachers' adoption of mobile apps to teach science. Figure 1 presents the proposed model.

\subsubsection{Technology Acceptance Model (TAM)}

The TAM is a model that explains the individuals' behavioral intentions to use a technological innovation. This theory was proposed by Davis (1989) as an extension of the Theory of Reasoned Action (TRA) and poses that individuals' technology acceptance is determined by two major variables, namely perceived ease of use and perceived usefulness. Perceived ease of use refers to the extent to which an individual believes that the use of a particular system is free of effort (Davis, 1989). On the other hand, perceived usefulness refers to the extent to which an individual believes that the use of a particular system would improve job performance (Davis, 1989). According to the TAM, perceived ease of use and perceived usefulness affect an individual's attitude toward the use of a system and perceived ease of use has a direct impact on perceived usefulness. In turn, the individual's intention to use a system is influenced by perceived usefulness (Teo \& Noyes, 2011).

Because of its simplicity and understandability, this theory has become one of the most widely used models to explain teachers' intentions to use technology. For example, Al-Emran et al. (2018) conducted a comprehensive analysis of 86 TAM studies related to mobile learning. The study highlighted the validity of the constructs of the TAM to examine the acceptance, attitudes, and actual use of mobile learning by students and teachers. Similarly, Scherer et al. (2019) conducted a

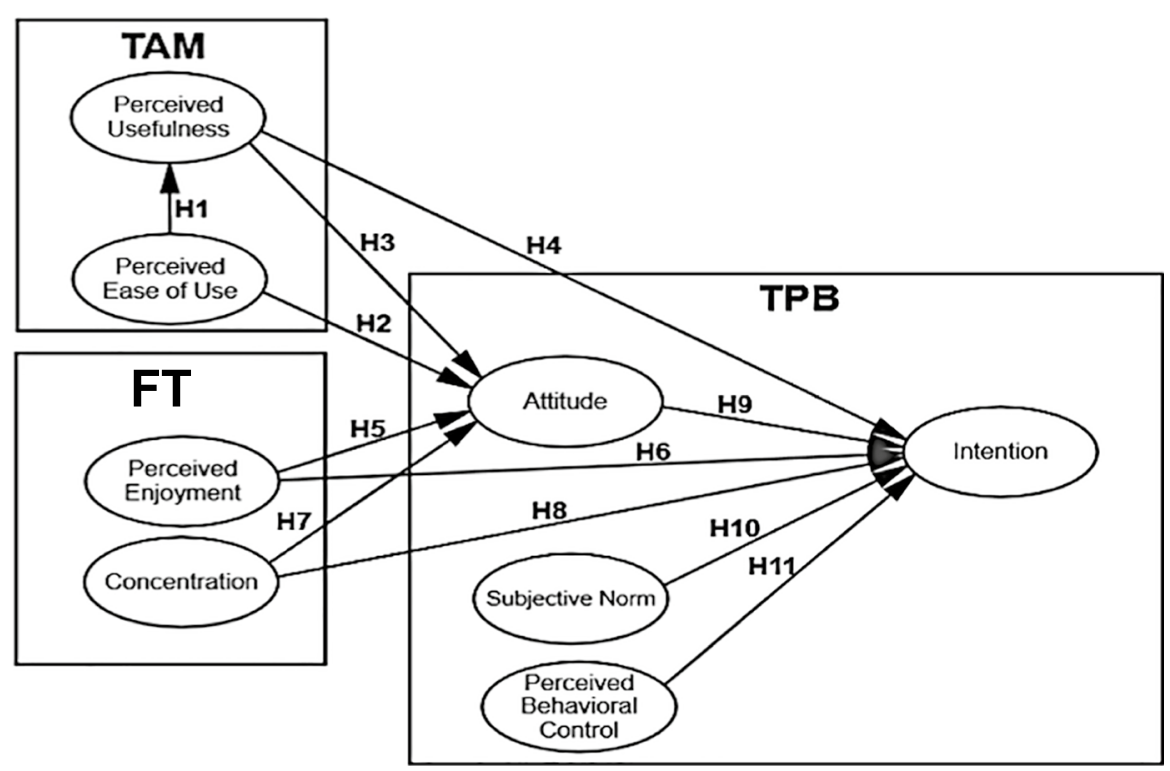

Fig. 1 Proposed model 
meta-analysis of 114 TAM studies to explain teachers' adoption of digital technology in education. The study validated the relevance of the TAM to explain behavioral intentions and the use of technology. The meta-analysis further highlighted that the TAM is equally relevant for several sub-groups, including pre-service and in-service teachers, teachers at different educational levels, and different countries. Finally, Granić and Marangunić (2019) conducted a systematic literature review of 71 studies to identify the importance of the TAM model according to the field of education, level of education, and deployment technology. The findings revealed that TAM is a leading scientific paradigm and credible model to facilitate the assessment of diverse technological deployments in educational contexts. Furthermore, the results indicated that perceived ease of use and perceived usefulness, are key elements to predict individuals' acceptance of technology in all the analyzed educational contexts.

Based on the previous background, we posit that the TAM is suitable for explaining science teachers' intentions to use mobile apps in their classes. Next, we establish the first, second, third, and fourth hypotheses of this study:

H1: Perceived ease of use is positively related to the science teachers' perceived usefulness of mobile apps (H1 : PEOU $\rightarrow P U)$.

H2: Perceived ease of use is positively related to the science teachers' behavioral attitudes toward mobile apps (H2 : PEOU $\rightarrow$ ATT).

H3: Perceived usefulness is positively related to the science teachers' behavioral attitudes toward mobile apps (H3 : PU $\rightarrow$ ATT).

H4: Perceived usefulness is positively related to the science teachers' behavioral intentions to use mobile apps (H4 : PU $\rightarrow I N T)$.

\subsubsection{Flow Theory (FT)}

The FT defines flow like a state of deep absorption in an activity that is intrinsically enjoyable (Csikszentmihalyi, 2008). People in this state perceive that their performance is pleasant and successful, and the activity is worth doing for its own. There is no single definition of the necessary conditions that lead to flow. Koufaris (2002) proposed one of the most widely used FT models in education, as the proposed constructs have been successfully validated to explain teachers intentions to use technology. Koufaris' model measures flow using three constructs: perceived enjoyment, perceived control, and concentration. In this model, perceived enjoyment refers to the extent to which the activity of using a specific system is perceived to be enjoyable in its own right, aside from any performance consequences resulting from system use (Venkatesh, 2000). On the other hand, concentration refers to the state of absolute absorption in an activity (Csikszentmihalyi, 2008). Finally, perceived control is defined as the level of an individual's control over the environment and the individual's actions (Koufaris, 2002). The study by Bower et al. (2020) and $\mathrm{Hu}$ et al. (Hu et al., 2020) state that perceived enjoyment is a key motivator for influencing teachers' attitude toward the use technology and, ultimately, teachers' intentions to use it. Similarly, perceived control is described as one of the constructs that most influences teachers' intentions to use technology (Somchai \& Damnoen, 
2020; Teo et al., 2016). Finally, concentration leads to optimal learning experiences and, consequently, it also influences teachers' attitude toward the use technology and intentions to use it (Shernoff et al., 2014). Therefore, considering the purpose of our study, we adopt the constructs proposed by Koufaris (2002) to identify the drivers of teachers' intentions to use mobile applications to teach science.

There is great potential for students to experience flow in the learning process. However, this potential is often wasted as some of the key conditions for flow are lacking in many of today's educational contexts. In this regard, Schmidt (2010) stresses the importance of analyzing students' educational experience from the perspective of FT to understand the factors that promote students' engagement in learning. In line with this, Oliveira et al. (2018) conducted a systematic literature review of 57 studies to identify the main benefits in bringing students to the flow state in technology-enhanced learning. The study found positive outcomes, highlighting students' learning, students' satisfaction, and students' in-depth reflective process. Concerning science education, the study by Ellwood and Abrams (2018) analyzed students' social interaction in inquiry-based science according to the FT. The study concluded that conditions that prompt flow state, including perceived enjoyment, perceived control, and concentration fostered enhanced student learning gains and motivation. In that sense, the study remarks the importance of emphasizing flow as a key part of the development process of the students. Finally, the study states that to promote flow, teachers must put more emphasis on fun, making learning so compelling that it seems there is no other option for students than to learn.

Based on the previous background, we posit that the constructs of the FT are suitable for explaining science teachers' intentions to use mobile apps in their classes. Next, we establish the fifth, sixth, seventh, and eighth hypotheses of this study. It is important to note that perceived control is similar to perceived behavioral control in the TPB, and therefore, we merged both constructs to postulate the $11^{\text {th }}$ hypothesis.

H5: Perceived enjoyment is positively related to the science teachers' behavioral attitudes toward mobile apps (H5 : PE $\rightarrow$ ATT).

H6: Perceived enjoyment is positively related to the science teachers' behavioral intentions to use mobile apps (H6 : PE $\rightarrow I N T$ ).

H7: Concentration is positively related to the science teachers' behavioral attitudes toward mobile apps (H7:CO $\rightarrow$ ATT).

H8: Concentration is positively related to the science teachers' behavioral intentions to use mobile apps (H8:CO $\rightarrow I N T)$.

\subsubsection{Theory of Planned Behavior (TPB)}

The TPB links the beliefs of an individual with the behavior of the individual. This theory was proposed by Icek Ajzen in 1985 (Ajzen, 1985) as a complement of the Theory of Reasoned Action (TRA) by Fishbein and Ajzen (1975). The TPB states that three factors, namely attitude, subjective norm, and perceived behavioral control, shape the behavioral intentions of an individual. In turn, behavioral intention is assumed to be the closest determinant of human social behavior. The TPB defines attitude as the extent to which an individual positively or negatively values the 
performance of certain behavior (Fishbein \& Ajzen, 1975). On the other hand, subjective norm refers to the perceived social pressure imposed by important referents, to engage or not in a behavior (Fishbein \& Ajzen, 1975). Finally, perceived behavioral control refers to individuals' perceptions about their abilities to perform a certain behavior (Icek, 1991).

Because of the volitional emphasis of the TPB, it has been successfully implemented to study many intentional aspects of educational technology. For example, the study by Valtonen et al. (2018) implemented the TPB to explain pre-service teachers' readiness to use information technologies in education. The study validated the utility of the three constructs of the TPB to explain individuals' intentions. Particularly, the study found subjective norm as the most significant construct to explain pre-service teachers' intentions to use information technologies in educational settings. Additionally, the study by Gretterand and Yadav (2018) implemented the TPB to explain pre-service teachers' thinking about teaching media literacy and the study by Sungur-Gül and Ateş (2021) tested the TPB to understand pre-service teachers' mobile learning readiness. Similarly to the study by Valtonen et al. (2018), this study validated the utility of the TPB to explain pre-service teachers' intentions use information technologies in education. However, this study found attitude as the most significant construct to explain pre-services teachers' intentions to use information technologies in educational settings. Finally, the study by Somchai and Damnoen (2020) implemented the TPB to explain teachers' intentions to continue to use online teaching at post Covid-19 pandemic. The study supported the utility of the TPB as a theory to analyze individuals' intentions related to technological education. Particularly, perceived behavioral control was found to be the most significant construct in explaining teachers' intentions to continue to use online teaching at post Covid-19 pandemic.

Based on the previous background, we posit that the constructs of the TPB are suitable for explaining science teachers' intentions to use mobile apps in their classes. Next, we establish the ninth, tenth, and eleventh hypotheses of this study:

H9: Behavioral attitude toward mobile apps is positively related to the science teachers' behavioral intentions to use mobile apps (H9 : ATT $\rightarrow I N T)$.

H10: Subjective norm is positively related to the science teachers' behavioral intentions to use mobile apps (H10 : SN $\rightarrow$ INT).

H11: Perceived behavioral control is positively related to the science teachers' behavioral intentions to use mobile apps (H11 : PBC $\rightarrow$ INT).

\section{Method}

\subsection{Sample and data collection}

The study was conducted based on cross-sectional study. The participants of the study were pre-service and in-service science teachers who were determined based on a voluntary basis using the convenience sampling method. In Turkey, pre-service science teachers are trained in accordance with the elementary school science 
curriculum during their four-year higher education. On the other hand, at the middle school level (from $5^{\text {th }}$ grade to $8^{\text {th }}$ grade), science courses are taught by in-service science teachers.

The data were collected in a classroom environment at middle schools and universities in several cities in Turkey. Initially, the data was collected from 792 preservice science teachers and 489 in-service science teachers. After the first examination on the scales, 78 outliers, incomplete, and unusable responses were excluded from the study. Hence, a total of 1203 usable scales were obtained from pre-service science teachers $(N=735)$ and in-service science teachers $(N=468)$ showing a valid response rate of $93.91 \%$. Regarding the pre-service teachers, $66.4 \%$ were female and $33.6 \%$ were male, with ages between 17 and 26 years $\left(M_{\text {age }}=21.8\right)$. As for in-service science teachers, $57.9 \%$ were female and $42.1 \%$ were male, with ages between 24 and $63\left(M_{\text {age }}=41.2\right)$, and average occupational experiences was 18 years. A great majority of them (85.26\%) had a bachelor's degree, while $14.74 \%$ completed postgraduate education.

\subsubsection{Measurement tools}

The scales in the current study were adapted from earlier studies (see Table 1). The preparation of these scales from the first to the final version consists of several stages. First, initial scale items were arranged after extant literature was reviewed. Second, the first version of the scale items was pre-tested with 225 pre-service and in-service science teachers. Third, as the original version of the items and constructs are in English and the scales in the current study were prepared in Turkish, we used the blind translation-back-translation method to ensure consistency and accuracy (Bracken \& Barona, 1991). The translated scales were comprehensively reviewed and improved by academicians who have language proficiency in both Turkish and English and have sufficient knowledge about national and international literature on the subject of this study. In addition, the scale was completed by three experts in the field of the department of science education and computer and instructional technologies.

The self-determined scales consist of four parts. The first part of the scales includes items and constructs (perceived ease of use, three items and perceived usefulness, three items) involved in the TAM. Second, perceived enjoyment (three items) and concentration (three items) were obtained from the FT. In the third stage, attitude (four items), subjective norm (two items), and perceived behavioral control (three items) were operationalized in the TBP. Finally, intention was measured with four items. A total of 25 items were evaluated with a seven-point Likert type scale ranging from "Strongly disagree" (1) to "Strongly agree" (7). Table 1 presents items, constructs, and sources of scales used in the study.

\subsubsection{Data analysis}

The data were analyzed using SPSS and AMOS statistical programs. In accordance with Anderson and Gerbing (1988) two-step approach was used using maximum likelihood estimation. Firstly, a measurement model was estimated by conducting 


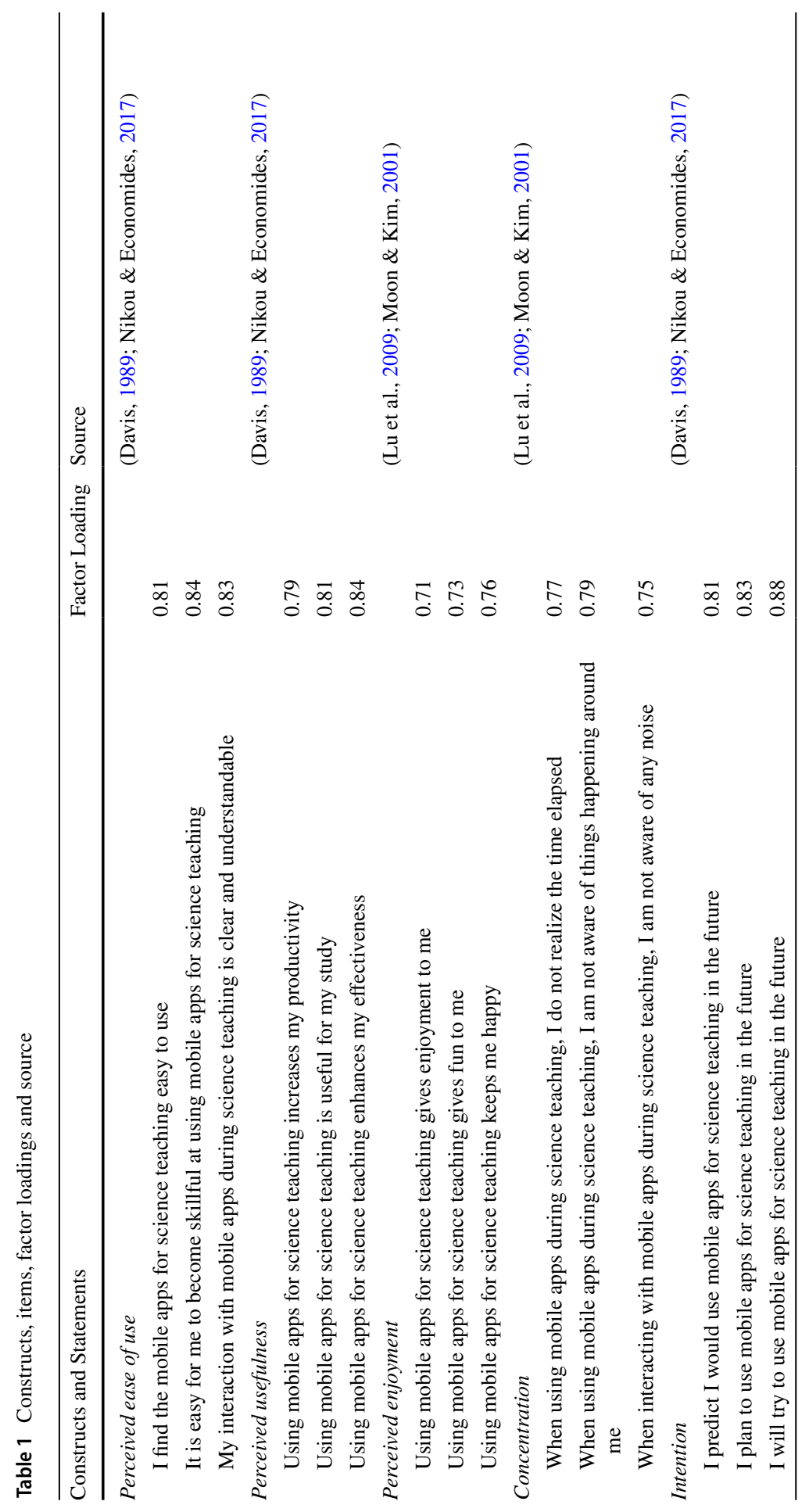




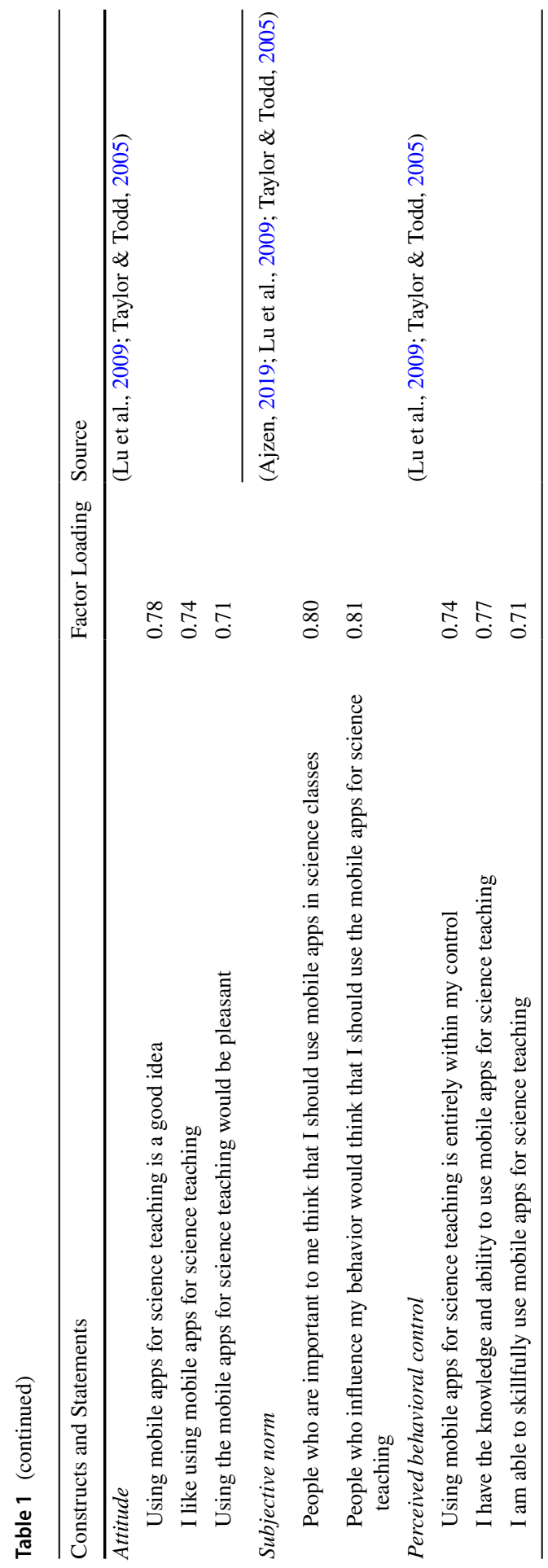


confirmatory factor analysis (CFA), and then structural equation modeling (SEM) was used to evaluate and compare the proposed model and test the hypotheses.

The first step of the analysis showed that the measurement model fit the data very well (comparative fit index $[\mathrm{CFI}]=0.95$, The goodness of fit index $[\mathrm{GFI}]=0.93$, The normed fit index $[\mathrm{NFI}]=0.95$, Tucker-Lewis Index $[\mathrm{TLI}]=0.94$, standardized root mean squared residual $[\mathrm{SRMR}]=0.04$, root mean square error of approximation $[\mathrm{RMSEA}]=0.05)$. Internal consistency of the data was examined via Cronbach's alpha $(\alpha)$ and composite reliability and the results indicated that $\alpha$ values for each variable were higher than the recommended value of 0.07 (Bagozzi \& Yi, 1988) and all the values of composite reliability were ranged from 0.78 to 0.91 which were greater than the recommended value of 0.6 (Bagozzi \& Yi, 1988). In addition, construct validity was tested using convergent validity and discriminant validity (Hair et al., 2017; Kline, 2015). The results of construct validity indicated that since all the values of average variance extracted (AVE) were larger than the suggested value of 0.5 (Hair et al., 2017), convergent validity was provided. Discriminant validity was also provided because all values of the square root of the AVE were exceeded the correlation coefficients of constructs (Hair et al., 2017). Results toward the measurement model are involved in Table 2.

\section{Results}

\subsection{Goodness of fit and predictive power of structural model}

The current study merged TPB, TAM, and FT and proposed a more robust model to understand pre-service and in-service science teachers' intention to use mobile apps for science teaching. The goodness of fit results showed that the proposed model, TPB, TAM, and FT adequately fit the data. Results comparing models with the proposed model revealed that the proposed model $\left(\chi^{2} / \mathrm{df}=2.14\right)$ has superior fit to that of TPB $\left(\chi^{2} / \mathrm{df}=2.30\right)$, TAM $\left(\chi^{2} / \mathrm{df}=2.69\right)$, and FT $\left(\chi^{2} / \mathrm{df}=2.99\right)$. The model

Table 2 Results toward the measurement model

\begin{tabular}{llllllllllll}
\hline Constructs & 1 & 2 & 3 & 4 & 5 & 6 & 7 & 8 & $\alpha$ & AVE & CR \\
\hline 1. PEOU & $\mathbf{0 . 8 2}$ & & & & & & & & 0.81 & 0.68 & 0.87 \\
2. PU & 0.498 & $\mathbf{0 . 8 1}$ & & & & & & & 0.83 & 0.66 & 0.85 \\
3. $A T T$ & 0.478 & 0.58 & $\mathbf{0 . 7 5}$ & & & & & & 0.77 & 0.57 & 0.84 \\
4. $S N$ & 0.26 & 0.37 & 0.37 & $\mathbf{0 . 8 1}$ & & & & & 0.74 & 0.65 & 0.79 \\
5. $P B C$ & 0.52 & 0.29 & 0.49 & 0.46 & $\mathbf{0 . 7 4}$ & & & & 0.79 & 0.55 & 0.78 \\
6. PE & 0.39 & 0.44 & 0.64 & 0.47 & 0.26 & $\mathbf{0 . 7 3}$ & & & 0.77 & 0.54 & 0.78 \\
7.CON & 0.12 & 0.19 & 0.27 & 0.23 & 0.11 & 0.30 & $\mathbf{0 . 7 7}$ & & 0.71 & 0.59 & 0.81 \\
8. INT & 0.46 & 0.59 & 0.58 & 0.28 & 0.58 & 0.52 & 0.32 & $\mathbf{0 . 8 4}$ & 0.89 & 0.71 & 0.91 \\
Mean & 5.21 & 5.01 & 4.84 & 4.11 & 4.50 & 4.41 & 3.91 & 4.66 & - & - & - \\
SD & 1.12 & 1.06 & 0.92 & 1.11 & 1.11 & 1.09 & 1.44 & 1.07 & - & - & - \\
\hline
\end{tabular}

Diagonal and bold values show the square root of AVE 
$\left(\mathrm{R}^{2}=0.52\right)$ also had a superior ability to explain intention than TPB $\left(\mathrm{R}^{2}=0.47\right)$, TAM $\left(\mathrm{R}^{2}=0.42\right)$, and FT $\left(\mathrm{R}^{2}=0.39\right)$. Model fit indices and predictive powers of models in the study are involved in Table 3.

\subsection{Hypothesis testing}

SEM was used to examine the relationships among constructs in the proposed model. The results of hypothesis testing showed that $P E O U$ had a positive influence on both $P U(\beta=0.49, \mathrm{p}<0.001)$ and ATT $(\beta=0.34, \mathrm{p}<0.001)$, supporting H1 and H2. Paths from PU to ATT $(\beta=0.32, \mathrm{p}<0.001)$ and $\operatorname{INT}(\beta=0.36, \mathrm{p}<0.001)$ were statistically significant, thus $\mathrm{H} 3$ and $\mathrm{H} 4$ were supported. $\mathrm{H} 5$ and $\mathrm{H} 6$ were also supported as a positive direct influence of PE on ATT $(\beta=0.48, \mathrm{p}<0.001)$ and INT to use mobile apps for science teaching $(\beta=0.22, \mathrm{p}<0.01)$. It was also found that the paths from $C O$ to $A T T(\beta=0.16, \mathrm{p}<0.01)$ and $I N T(\beta=0.19, \mathrm{p}<0.01)$ were statistically significant, supporting H7and H8. Finally, among the constructs of TPB, ATT $(\beta=0.28, \mathrm{p}<0.001), S N(\beta=0.21, \mathrm{p}<0.01)$, and $P B C(\beta=0.24, \mathrm{p}<0.01)$ were positively related to INT to use mobile apps for science teaching. Therefore, H9, H10, and H11 were supported. Results toward indirect relationships showed that $P E O U$ had a positive indirect impact on $A T T(\beta=0.15, \mathrm{p}<0.05)$. In addition, $P E O U(\beta=0.11, \mathrm{p}<0.05), P U(\beta=0.12, \mathrm{p}<0.05), C O(\beta=0.10, \mathrm{p}<0.05)$ and $P E(\beta=0.13, \mathrm{p}<0.05)$ were indirectly related to INT to use mobile apps for science teaching. Finally, within the proposed model, about $24 \%$ of the total variance in $P U$ was explained by $P E O U$. In addition, $P E O U, P U, P E$, and $C O$ accounted for $49 \%$ of the variance in ATT. Lastly, $52 \%$ of the variance in INT was explained by its antecedents. Results of the hypothesis test are indicated in Table 4 and Fig. 2.

\subsection{Examining the moderating effects of sample type}

In the study, the invariance test for measurement and structural models was performed to test the moderating effect of sample type (Kline, 2015). In this study, as sample type, 735 pre-service science teachers and 468 in-service science teachers were involved in the study.

During the moderating analysis, in the first stage, statistical significance was tested between the non-restrict model and the full-metric invariance model. In the second stage, the baseline model and the nested model were compared in a

Table 3 Results of goodness of fit and predictive powers

\begin{tabular}{lllllllllll}
\hline & $\chi^{2}$ & df & $\chi^{2} / \mathrm{df}$ & GFI & IFI & TLI & CFI & RMSEA & SRMR & $\mathrm{R}^{2}$ \\
\hline Proposed model & 982.42 & 458 & 2.14 & 0.94 & 0.95 & 0.96 & 0.96 & 0.03 & 0.03 & 0.52 \\
TPB & 578.71 & 252 & 2.30 & 0.93 & 0.93 & 0.93 & 0.94 & 0.04 & 0.04 & 0.47 \\
TAM & 612.98 & 228 & 2.69 & 0.92 & 0.91 & 0.91 & 0.92 & 0.05 & 0.05 & 0.42 \\
FT & 442.78 & 148 & 2.99 & 0.91 & 0.91 & 0.90 & 0.91 & 0.05 & 0.06 & 0.39 \\
\hline
\end{tabular}


Table 4 SEM results of the conceptual proposed model

\begin{tabular}{lllll}
\hline Hypothesis & Pathway & Path coefficient $(\beta)$ & t-value & State \\
\hline $\mathrm{H} 1$ & $P E O U \rightarrow P U$ & $0.49^{* * *}$ & 7.82 & Supported \\
$\mathrm{H} 2$ & $P E O U \rightarrow A T T$ & $0.34 * * *$ & 6.51 & Supported \\
$\mathrm{H} 3$ & $P U \rightarrow A T T$ & $0.32^{* * *}$ & 6.11 & Supported \\
$\mathrm{H} 4$ & $P U \rightarrow I N T$ & $0.36^{* * *}$ & 6.88 & Supported \\
$\mathrm{H} 5$ & $P E \rightarrow A T T$ & $0.48^{* * *}$ & 7.55 & Supported \\
$\mathrm{H} 6$ & $P E \rightarrow I N T$ & $0.22^{* *}$ & 4.88 & Supported \\
$\mathrm{H} 7$ & $C O \rightarrow A T T$ & $0.16^{* *}$ & 4.02 & Supported \\
$\mathrm{H} 8$ & $C O \rightarrow I N T$ & $0.19 * *$ & 4.42 & Supported \\
$\mathrm{H} 9$ & $A T T \rightarrow I N T$ & $0.28^{* * *}$ & 5.62 & Supported \\
$\mathrm{H} 10$ & $S N \rightarrow I N T$ & $0.21^{* *}$ & 4.68 & Supported \\
$\mathrm{H} 11$ & $P B C \rightarrow I N T$ & $0.24 * *$ & 5.11 & Supported \\
Variance explained: & Indirect effect: & & & \\
$\mathrm{R}^{2}(P U)=0.24$ & $\beta P E O U \rightarrow A T T=0.15 *$ & & & \\
$\mathrm{R}^{2}(A T T)=0.49$ & $\beta P E O U \rightarrow I N T=0.11 *$ & & & \\
$\mathrm{R}^{2}(I N T)=0.52$ & $\beta P U \rightarrow I N T=0.12 *$ & & & \\
& $\beta P E \rightarrow I N T=0.13 *$ & & & \\
& $\beta C O \rightarrow I N T=0.10 *$ & & &
\end{tabular}

$* p<0.05, * * p<0.01, * * * p<0.001$

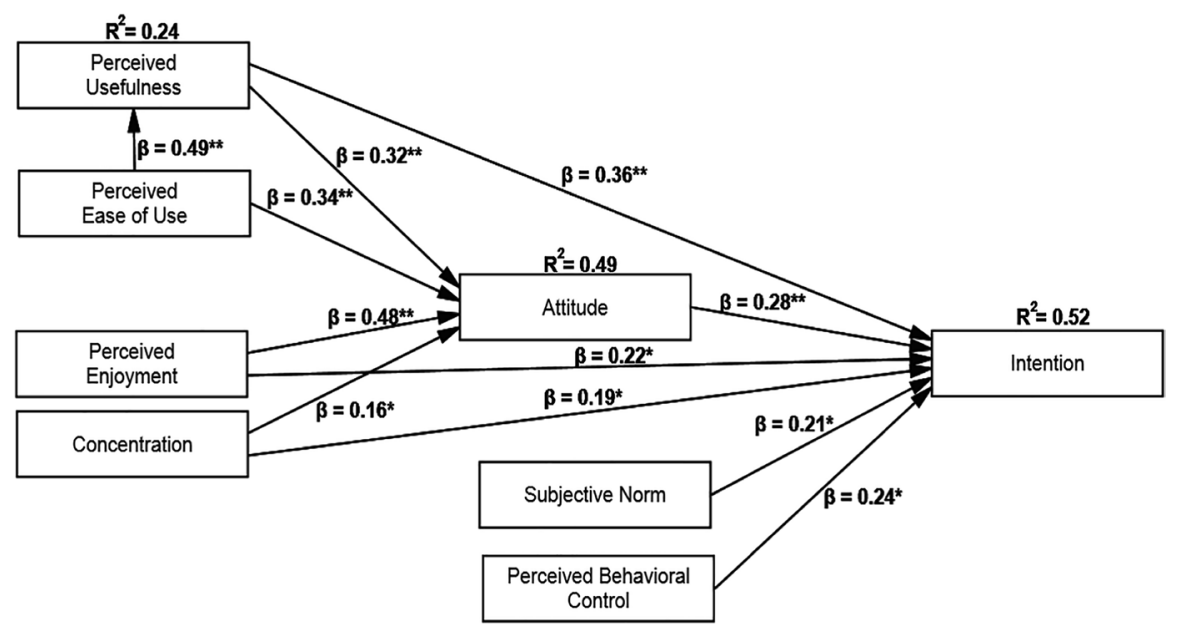

Note. ${ }^{*} p<0.01,{ }^{* *} p<0.001$

Fig. 2 Results from the hypothesis test

certain path across the groups. Data analysis showed that both non-restrict model $\left(\chi^{2}=1235.68, \mathrm{df}=646 ; \chi^{2} / \mathrm{df}=1.91, \mathrm{CFI}=0.95, \mathrm{IFI}=0.96, \mathrm{TLI}=0.95, \mathrm{RMSEA}=0.048\right)$ and full-metric invariance model $\left(\chi^{2}=1282.47, \mathrm{df}=671 ; \chi^{2} / \mathrm{df}=1.91, \mathrm{CFI}=0.95, \mathrm{IFI}=0.95, \mathrm{TLI}=0.95\right.$, RMSEA $\left.=0.049\right)$ generated a good fit to the data. It was also found that the chi-square difference test revealed that 
there was no significant difference between the non-restrict model and full-metric invariance model $\left(\Delta \chi^{2}(25)=46.79, \mathrm{p}>0.01\right)$. Accordingly, this finding supported the full-metric invariance.

Proposed relationships were added to full-metric invariance model to generate the baseline model. Result of the structural-invariance model showed that the baseline model is a great fit with data $\left(\chi^{2}=1536.74, \mathrm{df}=746 ; \mathrm{p}<0.001, \chi^{2} / \mathrm{df}=2.06, \mathrm{CFI}=0.91, \mathrm{IFI}=0.91, \mathrm{TLI}=0.90 \mathrm{RMSEA}=0.054\right)$.

As a result of comparing the baseline model with the nested model, a series of significant relationships were found. The paths from $P E\left(\Delta \chi^{2}(1)=4.45, \mathrm{p}<0.05\right)$ and $C O\left(\Delta \chi^{2}(1)=5.37, \mathrm{p}<0.05\right)$ to $I N T$ were significantly different between preservice teachers and in-service teachers. Results of the structural invariance test are presented in Table 5.

\section{Discussion and implications}

The proposed model combined the TPB, TAM, and FT into one comprehensive theoretical framework to examine pre-service and in-service science teachers' intention to use mobile apps for science teaching. In addition, the study investigated the mediating role of attitude and perceived usefulness on intention and the moderating importance of sample type are assumed important factors on teachers' behavioral intentions. All hypotheses in the proposed model were supported. In addition, the results of the study showed that attitude and perceived usefulness played a mediating role to explain behavioral intention. Furthermore, sample type had an important moderating variable to examine the influence of perceived enjoyment and concentration on pre-service and in-service science teachers' intention to use mobile apps for science teaching.

\subsection{Theoretical implications}

First, the positive role of mobile apps in science learning has been confirmed in many studies (Camilleri \& Camilleri, 2019), therefore, in this study, it is assumed that mobile apps help teachers in their teaching process. Some of earlier studies examined the role of psychological variables to predict to intention to use mobile applications in science education (e.g., Kalogiannakis \& Papadakis, 2019). However, there have been a few studies that specifically investigate factors affecting or in-service teachers' intentions to use mobile technologies such as ipads and mobile based assessment for science teaching (e.g., Hu \& Garimella, 2014; Nikou \& Economides, 2019). The results revealed in the present study are theoretically important since antecedents of both pre-service and in-service science teachers' behavioral intentions to use mobile apps for science teaching were first determined.

Second, the study attempted to integrate three theories including TPB, TAM, and FT so as to explain behavioral intentions toward the use of mobile apps in science courses within the context of educational technology. In past studies, the extended framework integrating belief-related, volitional, non-volitional, and motivation-based factors was applied in exploring individuals' various technology acceptance intentions (Cheng, 2019; Lu et al., 2009).Therefore, merging 


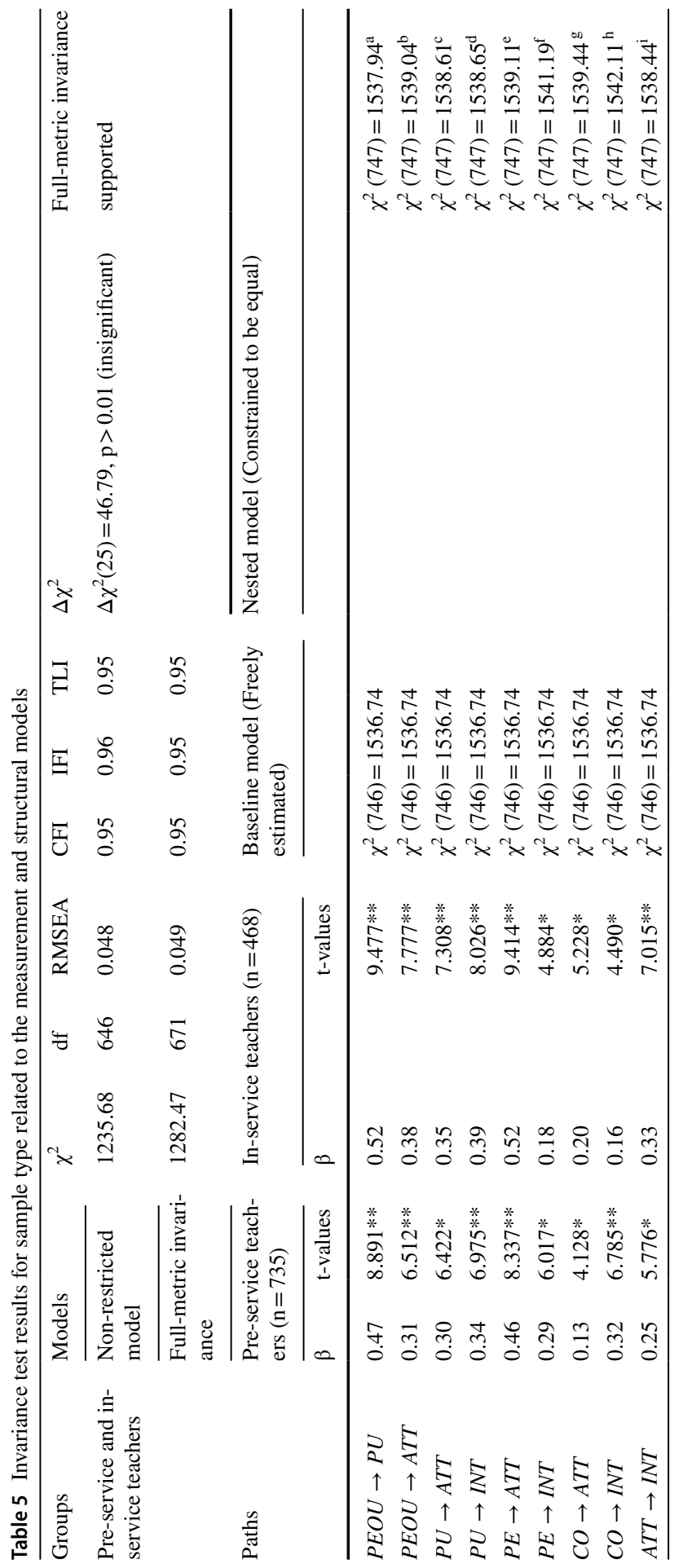




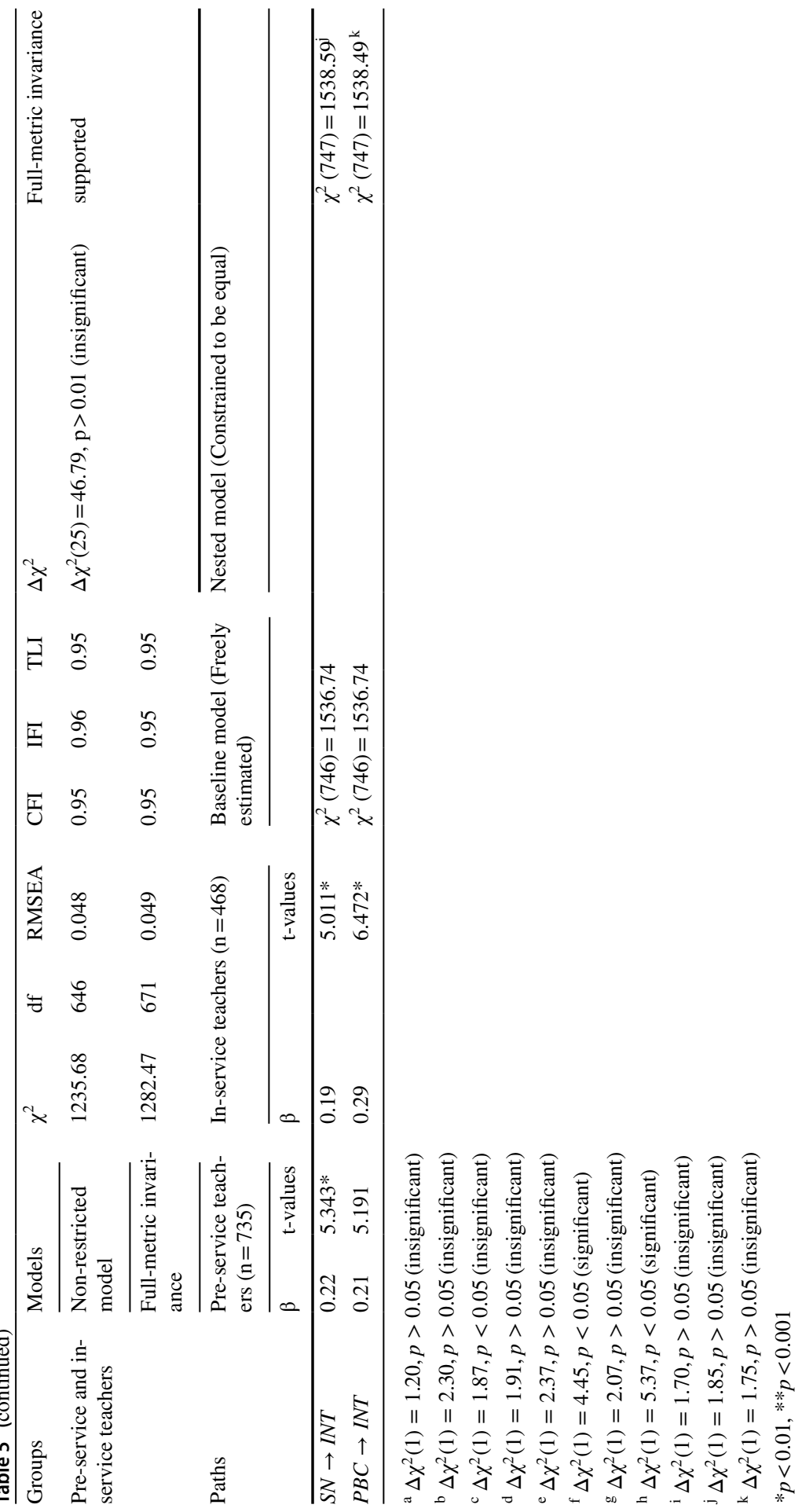


these models has been proposed as a holistic approach and has been confirmed to be robust in explaining individuals' behavioral intentions. Moreover, the results showed that each construct in the proposed model was significantly related to pre-service and in-service science teachers' behavioral intentions to use mobile apps for science teaching.

Third, the study results showed that the additional paths proposed by combining TPB, TAM, and FT were significantly supported. Specifically, perceived ease of use and perceived usefulness had a positive impact on attitude, which was positively related to intention. This implies that pre-service and in-service science teachers who believe that using mobile apps for science teaching would be free of effort and increases their productivity tend to evaluate this technology in science classes as positive. The results also indicated that the stronger the teachers' positive attitudes, the higher their intention to use mobile applications for science teaching. These findings are consistent with those of Teo et al. (2016) and supported the validity of TAM (Davis, 1989). In addition, perceived enjoyment and concentration played an essential role in explaining attitude and intention. In other words, increasing the enjoyment of using mobile apps for science teaching and the degree of focus on the effectiveness of using mobile apps strengthens teachers' attitudes, which in turn strengthens their intention to use mobile apps in science teaching. These results are consistent with some studies that identified the prominent role of the perceived enjoyment and concentration in explaining teachers' technology acceptance in education (Bower et al., 2020; Hu et al., 2020). Therefore, the study made important contributions to the literature by revealing the importance of these crucial constructs' relationships within the context of using mobile applications in science teaching.

Fourth, the study expanded the theoretical conceptual framework by emphasizing the moderating role of sample type in explaining behavioral intentions with regards to using mobile applications in science teaching in the integrated model that merged TPB, TAM, and FT. The results showed that sample type occupied an important moderating role in the relationships between perceived enjoyment and intention and concentration and intention. In particular, pre-service teachers demonstrated greater beta values than the in-service teachers in all the relationships. It can be inferred that when teachers start the teaching profession, they are less likely to have fun with mobile technology, and they are less likely to focus too much on that technology. Earlier studies supported these findings. For example, Venkatesh et al. (2012) stated that as people gather experience, the attraction of innovation that contributes to the impact of enjoyment and fun on technology use will decrease. In a similar vein, Lu et al. (2009) found that perceived enjoyment and concentration have a higher effect on technology acceptance intentions of students than working professionals. In this sense, the present study validated and expanded current literature by empirically revealing the moderating role of sample type within the context of the use of mobile applications in science teaching for the first time.

\subsection{Practical implications}

From a practical point of view, the study provided important results since the findings are useful to curriculum makers, teacher educators, school principals, 
policymakers, and mobile application developers. The study revealed that, similar to past studies, perceived ease of use, perceived usefulness, attitude, subjective norm, and perceived behavioral control play important role in understanding pre-service and in-service science teachers' intention to use mobile apps for science teaching. Therefore, teacher educators and curriculum makers should attach importance to the role of easiness and usefulness of mobile apps, favorable evaluations toward mobile apps, ideas of significant others, and non-volitional factors on pre-service teacher education. Another result from this study that should be considered is that pre-service and in-service science teachers are influenced differently by the same constructs (i.e., perceived enjoyment and concentration) and pre-service teachers who are younger than other group tend to have more fun from mobile applications in science teaching than in-service science teachers. Accordingly, considering the great importance of mobile applications in science education (Bano et al., 2018; Crompton et al., 2016; Jeno et al., 2019; Zydney \& Warner, 2016) and the significant increase in the number of studies carried out in recent years (Liu et al., 2021), mobile application developers and policymakers should bear in mind that mobile apps should be developed in a way that attracts the attention of in-service teachers and enables them to be more focused. It is also among the things that should be taken into consideration by those who have a voice in developing the program, that the apps should be made more fun while teachers are using them.

\subsection{Limitation and future research directions}

Although the present study had a variety of contributions to the literature, it has some limitations which need to be kept in mind for further research. The study is limited to only pre-service and in-service science teachers in Turkey, so generalization beyond this sample group can lead to misinterpretation and reduce external validity and therefore may cause sampling bias. In the study, as data were collected with self-reported scales, participants may not have stated their true thoughts and have answered in a way that supports social desirability. One of the important limitations is about testing the moderating effects of personal characteristics. More specifically, as there is a considerable disproportion in the distribution of some variables such as gender, the study only tested the moderator effect of sample type on intention to use mobile apps for science teaching. However, it is still unclear to what extent the moderator variables influence the intention to use educational technologies, especially mobile apps. Thus, future studies should continue to test the moderator role of a number of variables such as gender, age, experience, and sample group. Finally, since actual behavior towards the use of mobile apps was not involved in the proposed model, we used intention instead. However, even though intention is the best predictor of behavior (Icek, 1991), it doesn't measure actual behavior. Hence, in future studies, longitudinal research methods may provide the transforming of science teachers' intentions to behaviors related to the use of mobile applications in science teaching by performing indepth and within-person analyses. 


\section{References}

Ajzen, I. (1985). From Intentions to Actions: A Theory of Planned Behavior. In Springer Series in Social Psychology (pp. 11-39). Springer Berlin Heidelberg.

Ajzen, I. (2019). Constructing a Theory of Planned Behaviour Questionnaire. University of Massachusetts Amherst, 1-7. http://people.umass.edu/ aizen/pdf/tpb.measurement.pdf.

Al-Azawei, A., \& Alowayr, A. (2020). Predicting the intention to use and hedonic motivation for mobile learning: A comparative study in two Middle Eastern countries. Technology in Society, 62(June), 101325. https://doi.org/10.1016/j.techsoc.2020.101325

Al-Emran, M., Mezhuyev, V., \& Kamaludin, A. (2018). Technology Acceptance Model in M-learning context: A systematic review. Computers and Education, 125, 389-412. https://doi.org/10.1016/j. compedu.2018.06.008

Anderson, J. C., \& Gerbing, D. W. (1988). Structural equation modeling in practice: A review and recommended two-step approach. Psychological Bulletin, 103(3), 411-423.

Bagozzi, R. P., \& Yi, Y. (1988). On the evaluation of structural equation models. Journal of the Academy of Marketing Science, 16(1), 74-94.

Bano, M., Zowghi, D., Kearney, M., Schuck, S., \& Aubusson, P. (2018). Mobile learning for science and mathematics school education: A systematic review of empirical evidence. Computers and Education, 121(February), 30-58. https://doi.org/10.1016/j.compedu.2018.02.006

Bower, M., DeWitt, D., \& Lai, J. W. M. (2020). Reasons associated with preservice teachers' intention to use immersive virtual reality in education. British Journal of Educational Technology, 51(6), 22142232. https://doi.org/10.1111/bjet.13009

Bracken, B. A., \& Barona, A. (1991). State of the art procedures for translating, validating and using psychoeducational tests in cross-cultural assessment. School Psychology International, 12, 119-132. https://doi.org/10.1177/0143034391121010

Camilleri, A. C., \& Camilleri, M. A. (2019). Mobile learning via educational apps: An interpretative study. ACM International Conference Proceeding Series, 88-92.

Cheng, E. W. L. (2019). Choosing between the Theory of Planned Behavior (TPB) and the Technology Acceptance Model (TAM). Educational Technology Research and Development, 67(1), 21-37. https://doi.org/10.1007/s11423-018-9598-6

Crompton, H., Burke, D., Gregory, K. H., \& Gräbe, C. (2016). The use of mobile learning in science: A systematic review. Journal of Science Education and Technology, 25(2), 149-160. https://doi.org/ 10.1007/s10956-015-9597-x

Csikszentmihalyi, M. (2008). Flow: The Psychology of Optimal Experience. Harper Perennial Modern Classics.

Davis, F. (1989). Perceived usefulness, perceived ease of use, and user acceptance of information technology. Mis Quarterly, 13(3), 319-340.

Ellwood, R., \& Abrams, E. (2018). Student's social interaction in inquiry-based science education: How experiences of flow can increase motivation and achievement. Cultural Studies of Science Education, 13, 395-427. https://doi.org/10.1007/s11422-016-9769-x

Fishbein, M., \& Ajzen, I. (1975). Belief, attitude, intention, and behavior: An introduction to theory and research. Addison-Wesley.

Granić, A., \& Marangunić, N. (2019). Technology acceptance model in educational context: A systematic literature review. British Journal of Educational Technology, 50(5), 2572-2593. https://doi.org/10. 1111/bjet. 12864

Gretterand, S., \& Yadav, A. (2018). What do preservice teachers thinkabout teaching media literacy?An exploratory study using the Theory of Planned Behavior. Journal of Media Literacy Education, 10(1), 104-123.

Hair, J., Matthews, L., Matthews, R., \& Sarstedt, M. (2017). PLS-SEM or CB-SEM: Updated guidelines on which method to use. International Journal of Multivariate Data Analysis, 1(2), 107-123.

Hansen, J. M., Saridakis, G., \& Benson, V. (2018). Risk, trust, and the interaction of perceived ease of use and behavioral control in predicting consumers' use of social media for transactions. Computers in Human Behavior, 80, 197-206. https://doi.org/10.1016/j.chb.2017.11.010

Hill, R. J. (2017). Attitudes and Behavior. In Social Psychology (pp. 347-377). Routledge.

Hofeditz, M., Nienaber, A.-M., Dysvik, A., \& Schewe, G. (2017). "Want to" versus "have to": Intrinsic and extrinsic motivators as predictors of compliance behavior intention. Human Resource Management, 56(1), 25-49. 
Hu, H., \& Garimella, U. (2014). iPads for STEM teachers: A case study on perceived usefulness, perceived proficiency, intention to adopt, and integration in K-12 instruction. Journal of Educational Technology Development and Exchange (JETDE), 7(1), 49-66.

Hu, S., Laxman, K., \& Lee, K. (2020). Exploring factors affecting academics' adoption of emerging mobile technologies-an extended UTAUT perspective. Education and Information Technologies, 25, 4615-4635. https://doi.org/10.1007/s10639-020-10171-x

Icek, A. (1991). The Theory of Planned Behavior Organizational Behavior and Human Decision Processes. Organizational Behavior and Human Decision Processes, 50(2), 179-211.

Jeno, L. M., Adachi, P. J. C., Grytnes, J. A., Vandvik, V., \& Deci, E. L. (2019). The effects of m-learning on motivation, achievement and well-being: A Self-Determination Theory approach. British Journal of Educational Technology, 50(2), 669-683. https://doi.org/10.1111/bjet.12657

Kalogiannakis, M., \& Papadakis, S. (2019). Evaluating pre-service kindergarten teachers' intention to adopt and use tablets into teaching practice for natural sciences. International Journal of Mobile Learning and Organisation, 13(1), 113-127. https://doi.org/10.1504/IJMLO.2019.096479

Keller, J. M. (2009). Motivational design for learning and performance: The ARCS model approach. In Motivational Design for Learning and Performance: The ARCS Model Approach. Springer. https:// doi.org/10.1007/978-1-4419-1250-3.

Khlaif, Z. (2018). Teachers' perceptions of factors affecting their adoption and acceptance of mobile technology in K-12 settings. Computers in the Schools, 35(1), 49-67. https://doi.org/10.1080/07380569. 2018.1428001

Kline, R. B. (2015). Principles and practice of structural equation modeling (4nd ed.). Guilford Press.

Koufaris, M. (2002). Applying the Technology Acceptance Model and Flow Theory to Online Consumer Behavior. Information Systems Research, 13(2), 205-223.

Legris, P., Ingham, J., \& Collerette, P. (2003). Why do people use information technology? A critical review of the technology acceptance model. Information and Management, 40(3), 191-204. https:// doi.org/10.1016/S0378-7206(01)00143-4

Liu, C., Bano, M., Zowghi, D., \& Kearney, M. (2021). Analysing user reviews of inquiry-based learning apps in science education. Computers \& Education, 164, 1-14.

Lu, Y., Zhou, T., \& Wang, B. (2009). Exploring Chinese users' acceptance of instant messaging using the theory of planned behavior, the technology acceptance model, and the flow theory. Computers in Human Behavior, 25, 29-39. https://doi.org/10.1016/j.chb.2008.06.002

Manosuthi, N., Lee, J. S., \& Han, H. (2020). Predicting the revisit intention of volunteer tourists using the merged model between the theory of planned behavior and norm activation model. Journal of Travel and Tourism Marketing, 37(4), 510-532. https://doi.org/10.1080/10548408.2020.1784364

Martín-Páez, T., Aguilera, D., Perales-Palacios, F. J., \& Vílchez-González, J. M. (2019). What are we talking about when we talk about STEM education? A review of literature. Science Education, 103(4), 799-822. https://doi.org/10.1002/sce.21522

Moon, J.-W., \& Kim, Y.-G. (2001). Extending the TAM for a World-Wide-Web context. Information \& Management, 38(4), 217-230.

Nikou, S. A., \& Economides, A. A. (2017). Mobile-Based Assessment: Integrating acceptance and motivational factors into a combined model of Self-Determination Theory and Technology Acceptance. Computers in Human Behavior, 68, 83-95. https://doi.org/10.1016/j.chb.2016.11.020

Nikou, S. A., \& Economides, A. A. (2019). Factors that influence behavioral intention to use mobilebased assessment: A STEM teachers' perspective. British Journal of Educational Technology, 50(2), 587-600.

Oliveira, W., Bittencourt, I. I., Isotani, S., Dermeval, D., Brandão Marques, L., \& Frango Silveira, I. (2018). Flow Theory to Promote Learning in Educational Systems: Is it really relevant? Revista Brasileira De Informática Na Educação, 26(2), 29-59. https://doi.org/10.5753/rbie.2018.26.02.29

Scherer, R., Siddiq, F., \& Tondeur, J. (2019). The technology acceptance model (TAM): A meta-analytic structural equation modeling approach to explaining teachers' adoption of digital technology in education. Computers \& Education, 128, 13-35.

Schmidt, J. A. (2010). Flow in education. In International Encyclopedia of Education (pp. 605-611).

Shernoff, D. J., Csikszentmihalyi, M., Schneider, B., \& Shernoff, E. S. (2014). Student engagement in high school classrooms from the perspective of flow theory. In Applications of Flow in Human Development and Education (vol. 18, issue 2, pp. 475-494). Springer.

Somchai, P., \& Damnoen, P. (2020). Theory of Planned Behavior In Support for Post Covid-19 New Normalization Responses of Teachers Towards Online And Blended Learning. October. 
Sungur-Gül, K., \& Ateş, H. (2021). Understanding pre-service teachers' mobile learning readiness using theory of planned behavior. Educational Technology \& Society, 24(2), 44-57.

Tamilmani, K., Rana, N., \& Dwivedi, Y. (2017). A Systematic Review of Citations of UTAUT2 Article and Its Usage Trends. In Lecture Notes in Computer Science (vol. 10595, pp. 38-49). Springer.

Taufique, K. M. R., \& Vaithianathan, S. (2018). A fresh look at understanding Green consumer behavior among young urban Indian consumers through the lens of Theory of Planned Behavior. Journal of Cleaner Production, 183, 46-55. https://doi.org/10.1016/j.jclepro.2018.02.097

Taylor, S., \& Todd, P. A. (2005). Understanding information technology usage: A test of competing models. Information Systems Research, 6(2), 144-176.

Teo, T., \& Noyes, J. (2011). An assessment of the influence of perceived enjoyment and attitude on the intention to use technology among pre-service teachers: A structural equation modeling approach. Computers and Education, 57, 1645-1653. https://doi.org/10.1016/j.compedu.2011.03.002

Teo, T., Zhou, M., \& Noyes, J. (2016). Teachers and technology: Development of an extended theory of planned behavior. Educational Technology Research and Development, 64(6), 1033-1052. https:// doi.org/10.1007/s11423-016-9446-5

Turkish Ministry of National Education (2018). Science course curriculum, primary and middle school 3rd, 4th, 5th, 6th, 7th, and 8th grades. Ministry of National Education. https://mufredat.meb.gov. tr/Dosyalar/201812312311937-FEN\%20B\%C4\%B0L\%C4\%B0MLER\%C4\%B0\%20\%C3\%96\%C4\% 9ERET\%C4\%B0M\%20PROGRAMI2018.pdf

Udeani, U., \& Akhigb, J. (2020). In-service biology teachers' perceptions and pedagogical rating of two mobile learning applications recommended for learning biology in Nigerian secondary schools. The African Journal of Information Systems, 12(1), 5.

Valtonen, T., Kukkonen, J., Kontkanen, S., Mäkitalo-Siegl, K., \& Sointu, E. (2018). Differences in preservice teachers' knowledge and readiness to use ICT in education. Journal of Computer Assisted Learning, 34(2), 174-182. https://doi.org/10.1111/jcal.12225

Venkatesh, V. (2000). Determinants of perceived ease of use : Integrating control, intrinsic motivation, acceptance model. Inorganic Chemistry Communications, 11(3), 319-340.

Venkatesh, V., Thong, J., \& Xu, X. (2012). Consumer acceptance and use of information technology: Extending the unified theory of acceptance and use of technology. MIS Quarterly, 36(1), 157-178.

Zydney, J. M., \& Warner, Z. (2016). Mobile apps for science learning: Review of research. Computers and Education, 94, 1-17. https://doi.org/10.1016/j.compedu.2015.11.001

Publisher's note Springer Nature remains neutral with regard to jurisdictional claims in published maps and institutional affiliations. 